\title{
Door - to - door immunization strategy for improving access and utilization of immunization Services in Hard-to-Reach Areas: a case of Migori County, Kenya
}

Duncan N. Shikuku ${ }^{1 *}$ D, Maxwell Muganda', Soudie O. Amunga', Elly O. Obwanda², Alice Muga², Thomas Matete ${ }^{1}$ and Paul Kisia ${ }^{1}$

\begin{abstract}
Background: Access to quality essential healthcare services and vaccines for all is key to achieving universal health coverage. Inequities driven by differences in place of residence and socio-economic status persist among different communities hindering the achievement of sustained performance on immunization indicators. Innovative community-based Reach Every Child (REC) interventions at the sub-county and county level can reduce these local inequities. This study determines the effect of an enhanced door-to-door immunization strategy on improving immunization coverage in hard-to-reach areas of Migori.

Methods: This was a cross-sectional review of District Health Information System 2 immunization data for July and August 2018 for Migori County. During the presidential immunization rapid results initiative (RRI) in July 2018, poorly performing wards/facilities were mapped using the Quantum Geographic Information Systems methodology, and unreached rural-urban populations identified. Through review of facility level Kenya Expanded Programme on Immunization data, 64 health facilities with over 100 unimmunized children each between January 2017 and June 2018 in all sub-counties were prioritized. In August 2018, intensified fixed-point immunization services were offered within the prioritized facilities. Further, a 3-day door-to-door defaulter tracing by community health volunteers and household level immunization by nurses was conducted. Immunization coverage performance for access and utilization for the two periods were compared using z-tests/t-tests.

Results: Cumulatively, a total of 10,744 and 14,809 children were reached with immunization in July and August respectively for the 64 facilities. There were significant increases in the immunization coverage for BCG $(74.4 \%$ vs $89.9 \%, P=0.0001)$, Penta $1(96.2 \%$ vs $102 \%, P=0.0649)$, Penta $3(92.3 \%$ vs $112.1 \%, P=0.0001)$, MR1 $(81.7 \%$ vs $111.5 \%, P<0.0001)$ and the fully immunized children at 1 year $(78.6 \%$ vs $103.9 \%, P<0.0001)$. Penta 3 and MR1 drop-out rates (3.99\% vs $-9.86 \%, P=0.0007 ; 15.06 \%$ vs $-9.27 \%, P=0.0001$ respectively) decreased significantly. Similar significant effects were observed at the subcounty levels $(P<0.05)$.

Conclusion: Hard-to-reach populations require multiple REC strategies to reach every child with immunization. Health facilities should actively analyze and use routine immunization data and invest in community health strengthening systems to identify hard-to-reach areas to be targeted with outreaches to improve immunization coverage.
\end{abstract}

Keywords: Immunization, Hard - to - reach, Immunization coverage, Access and utilization

\footnotetext{
* Correspondence: dnshikuku@yahoo.com; duncan.shikuku@afyahalisi.org

${ }^{1}$ Afya Halisi Project, Migori County, Kenya

Full list of author information is available at the end of the article
}

(c) The Author(s). 2019 Open Access This article is distributed under the terms of the Creative Commons Attribution 4.0 International License (http://creativecommons.org/licenses/by/4.0/), which permits unrestricted use, distribution, and reproduction in any medium, provided you give appropriate credit to the original author(s) and the source, provide a link to the Creative Commons license, and indicate if changes were made. The Creative Commons Public Domain Dedication waiver (http://creativecommons.org/publicdomain/zero/1.0/) applies to the data made available in this article, unless otherwise stated. 


\section{Background}

Immunization saves an estimated 2-3 million lives every year [1] and is amongst the most cost - effective public health interventions for reducing global child morbidity and mortality [2, 3]. In Sub-Saharan Africa, despite the availability of vaccines against many infectious diseases and efforts from governments and their partners to vaccinate every child, the mortality rate from vaccine - preventable diseases for children under-five remains among the highest in the world [4].

Globally, Diphtheria-Tetanus-Pertussis (DTP3) coverage remains at $85 \%$ in 2017, leaving 19.9 million children vulnerable to vaccine preventable diseases. The 2018 Global Vaccine Action Plan (GVAP) report and other evidence indicates that continuing mass urbanization and migration, population growth, geographical and socio - economic inequities, place of residence and environmental disruptions in the communities continue to present major challenges to national immunization systems [1, 5-13] especially among the most disadvantaged, marginalized and hard-toreach populations in both rural and urban settings. Globally, it is estimated that $85 \%$ of children have been vaccinated with the first dose of measles vaccine by the age of 1 year. This is below the World Health Organization (WHO) recommended measles immunization coverage of at the minimum 95\%. Existence of pockets of low coverage in countries predisposes the region to large measles outbreaks causing many deaths [14]. For instance, in 2017, measles outbreaks were reported in three drought - affected countries in the Horn of Africa, including Ethiopia (3481 cases), Kenya (11 cases) and Somalia (7031 cases) [15]. The continued detection of circulating vaccine-derived poliovirus and the resurgence of measles outbreaks is further evidence that national immunization programs are not achieving the goal of reaching every child [1].

There have been significant improvements in the performance of the Expanded Program on Immunization (EPI) in Africa since its inception in 1974. However, there exist wide inter- and intra-country differences. While 35 (67\%) countries reported 80\% national DTP3 coverage in 2010, only $16(30 \%)$ countries reported at least $80 \%$ DTP3 coverage in $80 \%$ of their districts [10]. Many structural, financial, geographical and managerial barriers to providing universal access to immunization exist in the region. Despite these obstacles, the region has achieved coverage levels of about $72 \%$ for three doses of the diphtheria-tetanus-pertussis (DTP3) vaccine and the first dose of the measles vaccine.

Various strategies have been developed globally to guide implementation of EPI services and improve coverage. The Reaching Every Community/Child (REC) strategy is an innovative "bottoms" up approach that seeks to improve immunization coverage at health facilities. It has five key operational elements: re - establishing outreach vaccination services, supportive supervision to healthcare workers, linking services with communities, monitoring and use of immunization data for action and planning and management of resources through microplans [16]. Operationalization of the REC approach has contributed to increasing DPT3 coverage in Africa from 57 to $80 \%$ between 2000 and 2014. However, fewer than $50 \%$ of African countries achieved the GVAP national targets of 90\% DPT3 coverage by 2015 (16 countries), among which 13 maintained this level for 3 consecutive years. To maximize the full potential of vaccination, the GVAP [17] and the regional goals for Africa must target to achieve at least $90 \%$ vaccination coverage for routinely recommended vaccines at the national level and at least $80 \%$ in all the health districts/counties by 2020 [18]. Reviewing best practices and emerging issues as well as intensifying focus on closing the gaps in immunization services at the community level using innovative strategies can reduce the pockets of local inequities in REC. This includes more emphasis on communitybased interventions at the sub-district level emphasizing on reducing inequity in immunization coverage, integration of health services, delivering vaccines beyond infancy using a life course approach, focusing on urban, poor and marginalized populations, and paying special attention to insecure and conflict areas in Africa [16].

Kenya's fully immunization coverage rate as per the Kenya Demographic and Health Survey (KDHS) 2014 was $68 \%$ with stark differentials in immunization coverage existing across counties [19]. In 2017, only six of the 47 (13\%) counties had DPT3 coverage of at least $90 \%$ and a paltry four counties (9\%) had Measles/Rubella 1 coverage of at least $95 \%$ - the lowest coverage reported in the country since 2011 [20]. This was contributed by the protracted industrial action by healthcare workers for most periods of the year that paralyzed operations in the public health facilities [21, 22]. Other challenges affecting immunization in Kenya include the scheduling immunization hence missed opportunities, knowledge gap in immunization, inadequate capacity for storage of vaccines, myths and misconceptions around immunization by the community and economic barriers (faith - based organizations and private sector charging immunization services). This does not resonate with the country's national vaccines and immunization objectives of ensuring: equitable access to appropriate vaccination services for all persons; universal immunization of children with appropriate doses of Ministry of Health prescribed childhood vaccines; universal immunization of special risk groups with Ministry of Health approved priority vaccines; and optimum vaccination service delivery in response to specific situations of outbreak of life threatening vaccine - preventable diseases [23].

National county - level statistics show that Migori county had a low proportion of children 12-23 months (segregation at county level at 1 year not available) fully 
immunized at just 37\% in 2014 [24]. This included BCG, measles, three doses each of DTP and polio vaccine (excluding polio vaccine given at birth) and pneumococcal. The 2016 service statistics paint a picture of inequalities existing in the county. For instance, Kuria West and Suna East subcounties have fully immunized children (FIC) rates of below $70 \%$ and drop - out rates of above $10 \%$ between the first and third doses of Pentavalent vaccine. Out of the total 662,004 unvaccinated children nationally between Jan 2017 and May 2018, Migori had 16, 760 unvaccinated children [25]. This was $36 \%$ of the county's expected under 1 population for the year 2018 [26]. This paper determines the effect of an enhanced door-to-door immunization strategy on the immunization coverage in rural, urban and socio - economic hard-toreach areas of Migori County, Kenya following the national immunization rapid results initiative (RRI).

\section{Methods}

\section{Setting}

Migori County is found to the southwestern part of Kenya and borders Homa Bay County (North), Kisii County (North East), Narok (South East), Tanzania (West and South) and Lake Victoria to the West. The county also borders Uganda via Migingo islands in Lake Victoria. It is divided into eight subcounties. It has an area of $2586.4 \mathrm{~km}^{2}$ with an estimated population of 1 ,
119,184 in 2018 [26]. It has a population density of 353 per square kilometer and $43 \%$ of the population live below the poverty line [27]. The main economic activities include agriculture, fishing, manufacturing and small - scale mining. The county has both rural and urban populations. Poor road network within the county limits access \& utilization of health services especially during rainy seasons. The population around the Tanzania and Narok borders, fishing zones on the shores of Lake Victoria and the goldmines is migratory in nature depending on the existing cash flow and economic gains for daily living thereby playing disrupting continued uptake and utilization of health services including immunization. The county also has the Roho and Legio Maria religious sects that discourage use of health services (Fig. 1).

\section{Design}

This was a cross - sectional review of District Health Information System 2 (DHIS2) immunization data for July and August 2018 for Migori County. During the presidential immunization RRI in July 2018, poorly performing wards/facilities were mapped using the Quantum Geographical Information System (QGIS) application that supports viewing, editing and analysis of geospatial data for the two study periods (Fig. 2). The unreached rural-urban and socio - economic hard - to - reach

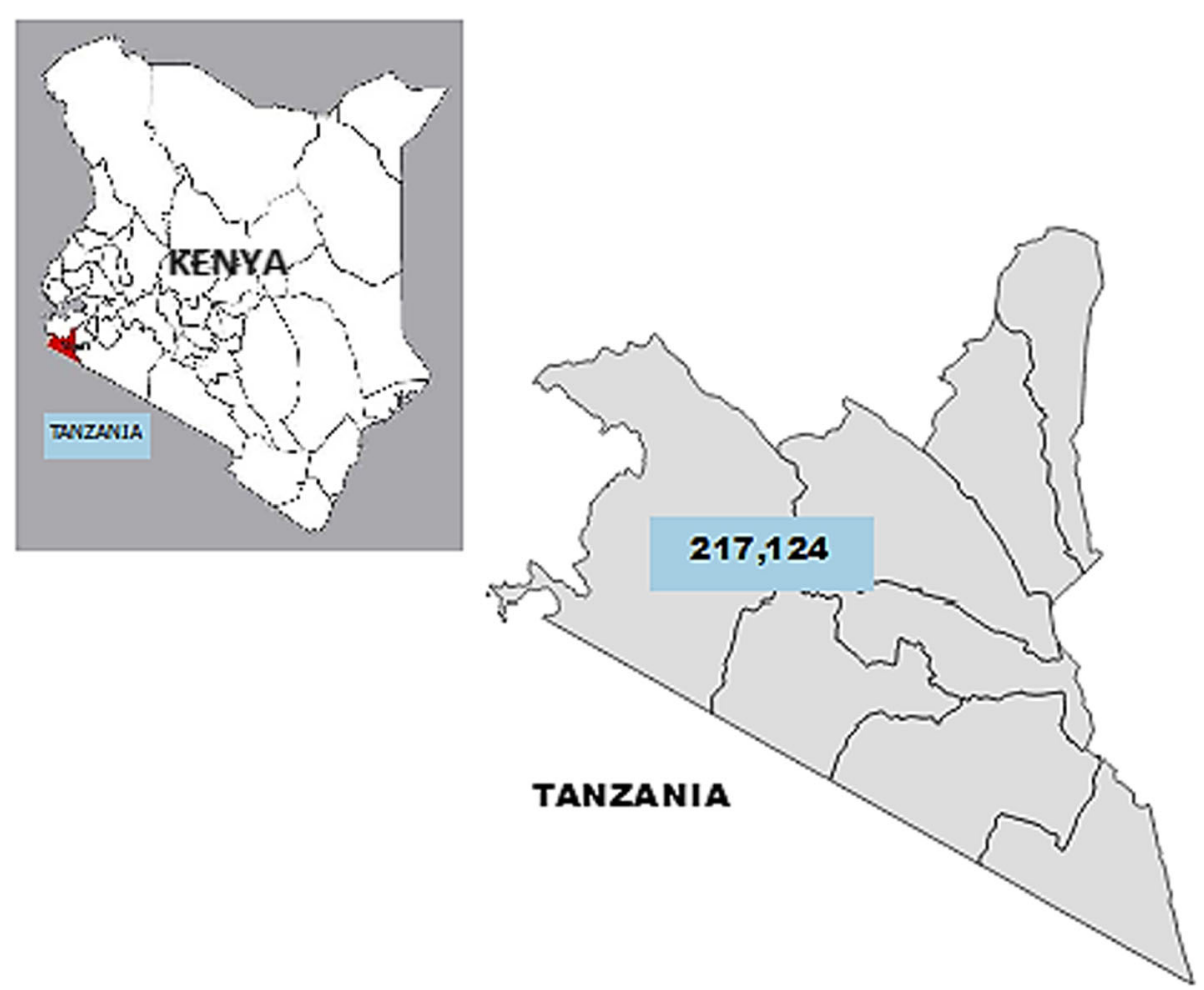

Fig. 1 Map of Migori County showing the children under 5 years population in 2018. Authors' own; generated using QGIS software 


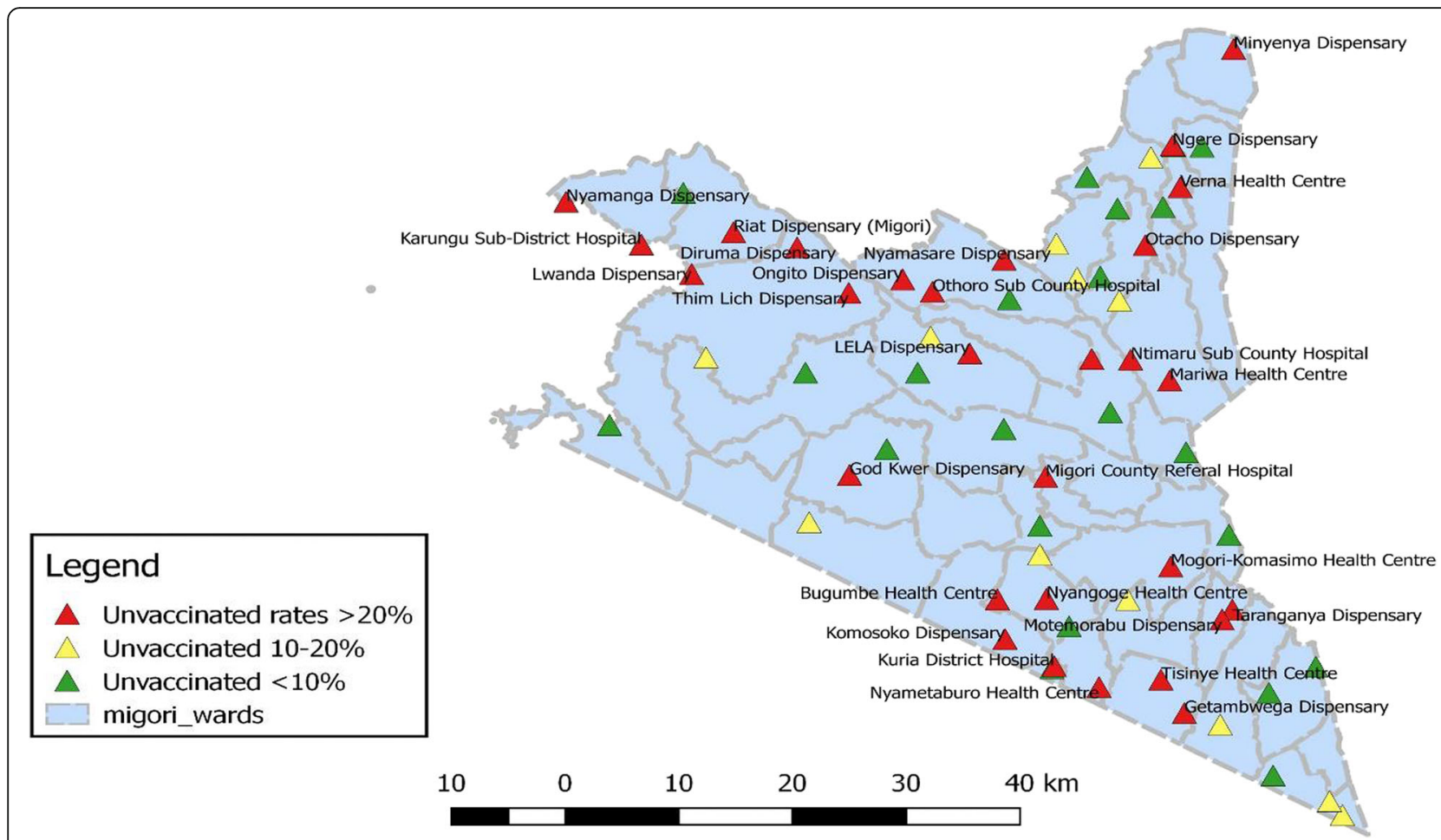

Fig. 2 QGIS distribution of the 64 health facilities with the highest unvaccinated children in Migori County in July 2018. Authors' own; generated using QGIS software. Door - to - door defaulter tracing, immunization and data collection

populations were identified. A total of 64 health facilities with over 100 unimmunized children each between January 2017 and June 2018 from all the eight subcounties were identified. In July, routine fixed-point immunization services were provided whereas in August, fixed - point plus a 3 - day enhanced door - to - door defaulter tracing by community health volunteers (CHVs) and household immunization by nurses was conducted in the 64 health facilities (out of $185 \mathrm{immu-}$ nizing facilities) with high burden of unimmunized children. Each health facility was allocated three CHVs under the supervision of the community health assistant (CHA) and one frontline healthcare worker who was the vaccinator. The exercise was supervised by the subcounties' health management teams (subcounty EPI coordinator and subcounty community strategy focal person). Overall supervision and coordination of logistics was provided by the county EPI logistics team. Importantly, the county, subcounties and the health facilities provide daily immunization services and had adequate stocks of routine vaccines both before and during the mobile immunization period. Afya Halisi, a 5year USAID funded project facilitated the ground logistics - transportation, lunches and coordination airtime for the county and subcounty teams and lunches and transportation for the healthcare workers and the CHVs during the mobile exercise.
The select facilities generated the immunization defaulters lists from the Immunization Permanent Registers $(\mathrm{MOH} 510)$ and the immunization diaries. These lists were assigned to the $\mathrm{CHVs}$ from the catchment areas who mapped out the community based on the unvaccinated children's burden. Community mobilization for the immunization services was conducted by the respective CHVs who provided households with information on benefits of starting and completing all the immunization services as per the prescribed $\mathrm{MOH}$ schedule. Together with the vaccinator, the team moved from house to house, scrutinized Mother Child Health $(\mathrm{MCH})$ records $(\mathrm{MOH} 216)$ or the immunization card, BCG scar mark as well as mother's or guardian's verbal verification to identify the unimmunized children. The $\mathrm{CHVs}$ had earlier received basic orientation on the $\mathrm{MCH}$ records. Importantly, in areas considered vast, the team of CHVs mobilized all the eligible unvaccinated children to central points where the vaccinator would visit together with the $\mathrm{CHA}$ and vaccinate the children. To maintain the cold - chain of the antigens, the vaccinators carried the vaccines in cold boxes and vaccine carriers each day. After vaccination, the vaccinator and the CHA would tally the immunization tally sheet (MOH 702), update the $\mathrm{MCH}$ records, counsel the client on the importance of scheduled immunizations and book for the next appointment for the subsequent follow 
- ups/immunizations. The CHVs and the vaccinators updated their immunization defaulters' records for reconciling/updating of the immunization permanent registers daily during the exercise. At the end of the exercise, the vaccinators updated the daily immunization data in the Immunization Services Uptake Summary $(\mathrm{MOH}$ 710) both the static/fixed point immunization services at the facility and the mobile immunization services. Data from 64 health facilities in Migori County were summarized and routinely entered in the national District Health Information System (DHIS2) by the subcounty health records officers. Technical assistance was provided to the health records team to ensure timely, complete, and accurate reporting of immunization indicators.

\section{Variables and measurements}

Immunization coverage as per the immunization schedule at birth -2 weeks, 6,10 \& 14 weeks, 9 months and at 18 months were computed as follows: birth -2 weeks, BCG and OPV 0; 6 weeks - Pentavalent 1; 10 weeks Pentavalent 2; 14 weeks - Pentavalent 3; 9 months Measles/Rubella 1; proportion of fully immunized children at 1 year and at 18 months - Measles/Rubella 2 . Drop - out rates for Pentavalent 3 and Measles 1 were also computed for utilization of immunization services. It is assumed that with adequate stocks for all antigens, each child receives all the due antigens at a given immunization visit as per the national immunization schedule.

\section{Data analysis}

Immunization data for July and August 2018 were extracted from the DHIS2 and entered in Microsoft Office Excel 2013 for data cleaning. Cleaned data was then exported to STATA version 12 for analysis. Differences in proportions of the coverages and drop - outs for the two time periods were compared through $\mathrm{z}$ - tests (for the 64 facilities)/paired $\mathrm{t}$ - tests (for the 8 subcounties) and $\mathrm{MOH}$ summary data and program reports were also reviewed to triangulate the information obtained from the DHIS2. Drop-out rates were calculated as follows: (i) Penta1 to Penta3 dropout rate $=($ Penta $1-$ Penta3 $) \div$ Penta $1 \times 100 \%$, where: Penta1 is the number (or percentage) receiving the first pentavalent vaccine dose and Penta 3 is the number (or percentage) receiving the third dose; (ii) Penta1 to Measles dropout rate $=($ Penta1 Measles) $\div$ Penta $1 \times 100 \%$, where: Penta1 is the number (or percentage) receiving the first pentavalent vaccine dose and Measles is the number (or percentage) receiving the Measles dose [28]. Our study was not only interested in the significance test alone. The use of the parametric tests allowed us to acknowledge the special population from which the samples came, and this is best done with estimates of parameters and confidence intervals [29]. Confidence intervals were calculated at the $95 \%$ level and $\mathrm{P}$ - values $\leq 0.05$ were considered statistically significant.

\section{Results}

Number of children immunized by age per key antigen

Overall, there was a marked improvement in the coverage by facilities in the number of unimmunized children compared to the previous routine fixed immunization service delivery (Fig. 3).

The findings indicate an increase in the total number of children immunized per antigen and by age from July to August (facilities: 10744 vs 14,809; subcounties: 20543 vs 25,550 ) as indicated in Table 2 below. At the facility level, the increase was more marked in children reached over the age of 1 year for BCG (19 times), Pentavalent 1 (22 times), Pentavalent 3 (19 times), MR1 (5 times) and MR2 (9 times) antigens as per the recommended immunization schedule. About 7 \% (296 of 4396) of the children who received MR1 were above the age of 1 year. Similarly, about 30\% (1211 of 4079) of the children received MR2 beyond 2 years of age. At the subcounty level, similar trends were observed as follows: Pentavalent $1>1$ year (22 times), Pentavalent $3>1$ year (11 times) and MR2 $>2$ years ( 6 times) (Table 1$)$.

\section{Facilities immunization coverage and drop - outs for July and august 2018}

Vaccination coverage by antigen for the facilities indicated that OPV 0 and BCG had lower coverages (less than $90 \%$ ) of the expected per antigen for the two reference periods (OPV 0: 75.67 vs 84.76 and BCG: 74.44 vs 89.94). Vaccine coverages significantly increased from July to August for OPV $0(75.6-84.8 \%, P=0.0008, \mathrm{CI}=$ 3.57-14.43), BCG (74.4-89.9\%, $P=0.0001, \quad \mathrm{CI}=8.01-$ 14.98), Pentavalent 3 (92.4-112.0\%, $P=0.0001, C I=$ 9.96-29.52) and Measles/Rubella 1 (81.7-111.5\%, $P<0.0001, \quad C I=19.97-39.61)$. The proportion of children fully immunized by 1 year of age increased significantly from 78.56 to $103.86(P<0.0001, \mathrm{CI}=$ 16.09-34.5). Drop - out rates for Penta 3 and Measles/ Rubella 1 decreased significantly $(P<0.05)$ (Table 2$)$.

\section{Subcounties immunization coverage and drop - outs for July and august 2018}

The 64 facilities with the high numbers of unimmunized children had a net effect on the overall vaccination coverage and drop - outs per antigen at the subcounties' level. All the vaccine coverages for OPV 0, BCG, Pentavalent 1 , Pentavalent 3 and Measles/Rubella 1 were above $90 \%$ in August with the highest gains observed in Pentavalent 3 and Measles/Rubella 1. Drop - outs in Pentavalent 3 and Measles/Rubella 1 were all less than 


\section{Legend}

A Unvaccinated rates $>20 \%$ Unvaccinated rates $10-20 \%$

A Unvaccinated rates $<10 \%$ migori_wards

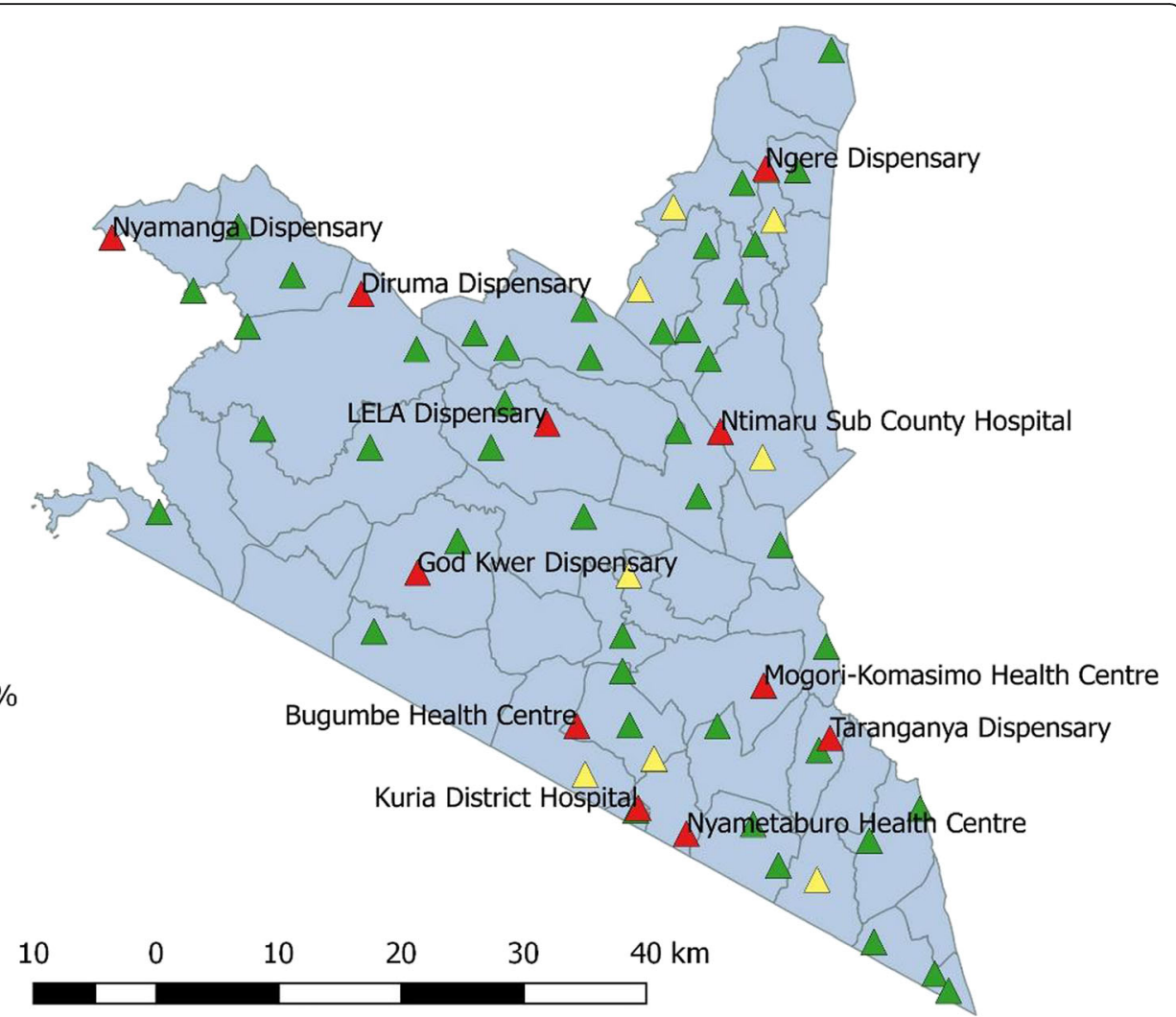

Fig. 3 QGIS distribution of the unvaccinated children in the 64 facilities after the mobile immunization strategy in Migori County in August 2018. Authors' own; generated using QGIS software

Table 1 Total number of children immunized for July and August 2018 per antigen

\begin{tabular}{|c|c|c|c|c|c|c|}
\hline & \multicolumn{3}{|c|}{ Total immunized (64 facilities) } & \multicolumn{3}{|c|}{ Total immunized (8 subcounties) } \\
\hline & July 2018 & Aug 2018 & $\%$ increase & July 2018 & Aug 2018 & $\%$ increase \\
\hline OPV 0 & 2053 & 2205 & 7.4 & 3337 & 3719 & 11.4 \\
\hline BCG $<1 \mathrm{yr}$ & 2016 & 2301 & 14.1 & 3562 & 4019 & 12.8 \\
\hline BCG $>1 \mathrm{yr}$ & 1 & 19 & 1800.0 & 9 & 25 & 177.8 \\
\hline PENTA $1<1 \mathrm{yr}$ & 2068 & 2163 & 4.6 & 3863 & 3999 & 3.5 \\
\hline PENTA $1>1 \mathrm{yr}$ & 1 & 22 & 2100.0 & 1 & 22 & 2100.0 \\
\hline PENTA $2<1 \mathrm{yr}$ & 1874 & 2225 & 18.7 & 3627 & 4053 & 11.7 \\
\hline PENTA $2>1 \mathrm{yr}$ & 4 & 30 & 650.0 & 7 & 35 & 400.0 \\
\hline PENTA $3<1 \mathrm{yr}$ & 1952 & 2324 & 19.1 & 3711 & 4242 & 14.3 \\
\hline PENTA $3>1 \mathrm{yr}$ & 4 & 74 & 1750.0 & 7 & 77 & 1000.0 \\
\hline $\mathrm{MR} 1<1 \mathrm{yr}$ & 1738 & 2362 & 35.9 & 3547 & 4326 & 22.0 \\
\hline MR1 > $1 \mathrm{yr}$ & 53 & 243 & 358.5 & 108 & 331 & 206.5 \\
\hline MR2 < 2 yrs & 907 & 1961 & 116.2 & 1888 & 3088 & 63.6 \\
\hline MR2 > 2 yrs & 126 & 1085 & 761.1 & 213 & 1333 & 525.8 \\
\hline TOTAL & 10,744 & 14,809 & 37.8 & 20,543 & 25,550 & 24.4 \\
\hline $\mathrm{FIC}$ at $1 \mathrm{yr}$ & 1671 & 2230 & 33.5 & 3412 & 4120 & 20.8 \\
\hline
\end{tabular}

BCG Bacille Calmette Guerin, PENTA Pentavalent (Diphtheria-Tetanus-Pertussis-Hepatitis B-Hemophilus influenza type b), MR Measles/Rubella and FIC Fully Immunized Child 
Table 2 Two - point comparison of immunization coverage and drop - out per antigen for the 64 health facilities for the period of July and August 2018

\begin{tabular}{|c|c|c|c|c|c|c|}
\hline \multirow[t]{2}{*}{ OPVO coverage } & July & Aug & diff & $P$ - value & & $95 \% \mathrm{Cl}$ \\
\hline & 75.67 & 84.76 & 9 & $0.0008^{*}$ & 3.57 & 14.43 \\
\hline BCG coverage & 74.44 & 89.94 & 15.5 & $0.0001^{*}$ & 8.01 & 14.98 \\
\hline PENTA 1 coverage & 96.19 & 102.03 & 5.84 & 0.0649 & 1.76 & 13.44 \\
\hline PENTA 3 coverage & 92.35 & 112.09 & 19.74 & $0.0001^{*}$ & 9.96 & 29.52 \\
\hline Proportion of under 1 vaccinated against MR1 & 81.7 & 111.49 & 29.79 & $<0.0001^{*}$ & 19.97 & 39.61 \\
\hline Proportion of under 1 fully vaccinated (FIC) & 78.56 & 103.86 & 25.3 & $<0.0001^{*}$ & 16.09 & 34.5 \\
\hline PENTA 3 drop - out rate & 3.99 & -9.86 & -13.85 & $0.0007^{*}$ & -23.32 & -4.5 \\
\hline MR1 drop - out rate & 15.06 & -9.27 & -24.34 & $0.0001^{*}$ & -38.74 & -11.38 \\
\hline
\end{tabular}

OPV Oral Polio Vaccine, BCG Bacille Calmette Guerin, PENTA Pentavalent (Diphtheria-Tetanus-Pertussis-Hepatitis B-Hemophilus influenza type b), MR Measles/ Rubella and FIC Fully Immunized Child

${ }^{*} P \leq 0.05$ statistically significant

10\% (Pentavalent 3 drop - out: 3.97 vs $-5.28, P=$ $0.0084, \mathrm{CI}=-17.00--2.3)$ and MR1 drop - out: $8.02 \mathrm{vs}$ $-7.82, P=0.0006, \mathrm{CI}=-25.52-$-4.75) (Table 3).

\section{County's overall performance from Jan - sept 2018}

Overall, the month of August registered the highest coverage with at least 90\% coverage for all antigens and above $95 \%$ for MR1 as recommended (Table 4).

\section{Discussion}

The study was set to establish the effect of a door - to door mobile immunization strategy on immunization access and utilization in hard - to - reach areas. Overall, the findings are suggestive that mobile immunization strategy improved access to and utilization of immunization services among those in hard - to - reach areas. With half of the subcounties bordering Tanzania, there is always the cross - border migration that occur throughout the year (plus 'walk - in' clients from the migratory population in the neighboring Narok County) owing to the porous borders that can also explain in some way the high coverage (over 100\%) achieved during the mobile immunization services [30].

Vaccination coverage for birth doses (OPV 0 and BCG) and Measles/Rubella in the 64 facilities were below national target of $90 \%$ for doses recommended at 2 weeks of age for the two periods, indicating suboptimal access to immunization services. This finding is consistent with other studies conducted in urban and informal settings/slums $[9,13]$. Despite progress in vaccine development and immunization delivery systems worldwide, populations in rural, urban and social - economic hard - to - reach settings often have limited or no access to lifesaving vaccines, leaving them at increased risk for morbidity and mortality related to vaccine - preventable disease. Evidence suggests that strengthening community mapping and monitoring of all pregnant women and the under 1 population by the community health strategy units can ensure that the population accesses skilled maternal, newborn and child health services [10, 31, 32]. This therefore calls for more targeted planning and combined approaches consonant with the Global Immunization Vision and Strategy (GIVS) of "using a

Table 3 Two - point comparison of immunization coverage and drop - outs per antigen for the 8 subcounties

\begin{tabular}{|c|c|c|c|c|c|c|}
\hline \multirow[t]{2}{*}{ OPVO coverage } & \multirow{2}{*}{$\begin{array}{l}\text { July } \\
84.79\end{array}$} & \multirow{2}{*}{$\begin{array}{l}\text { Aug } \\
94.3\end{array}$} & \multirow{2}{*}{$\begin{array}{l}\text { diff } \\
9.5\end{array}$} & \multirow{2}{*}{$\begin{array}{l}P \text { - value } \\
0.0024^{*}\end{array}$} & \multicolumn{2}{|l|}{$95 \% \mathrm{Cl}$} \\
\hline & & & & & 3.99 & 15.03 \\
\hline BCG coverage & 86.91 & 97.71 & 10.8 & $0.0018^{*}$ & 4.84 & 16.74 \\
\hline PENTA 1 coverage & 97.53 & 101.19 & 3.66 & 0.1773 & 5.08 & 12.4 \\
\hline PENTA 3 coverage & 93.66 & 106.53 & 12.86 & $0.0021^{*}$ & 5.57 & 20.15 \\
\hline Proportion of under 1 vaccinated against MR1 & 89.71 & 109.1 & 19.39 & $0.001^{*}$ & 9.73 & 29.04 \\
\hline Proportion of under 1 fully vaccinated (FIC) & 85.98 & 103.85 & 17.86 & 0.0013 & 8.64 & 27.11 \\
\hline PENTA 3 drop - out rate & 3.97 & -5.28 & -9.25 & $0.0084^{*}$ & -17.00 & -2.3 \\
\hline MR1 drop - out rate & 8.02 & -7.82 & -15.84 & $0.0006^{*}$ & -25.52 & -4.75 \\
\hline
\end{tabular}

OPV Oral Polio Vaccine, BCG Bacille Calmette Guerin, PENTA Pentavalent (Diphtheria-Tetanus-Pertussis-Hepatitis B-Hemophilus influenza type b), MR Measles/ Rubella and FIC Fully Immunized Child

${ }^{*} P \leq 0.05$ statistically significant 
Table 4 County's overall coverage from January-August 2018

\begin{tabular}{|c|c|c|c|c|c|c|c|c|}
\hline Period & Jan & Feb & March & April & May & June & July & Aug \\
\hline OPV 0 coverage & 79.9 & 75.8 & 76.1 & 88.1 & 92.4 & 78.8 & 83.6 & 93.2 \\
\hline BCG Coverage & 90.7 & 76.1 & 97.4 & 91.9 & 95.9 & 83.9 & 85.4 & 96.4 \\
\hline PENTA 1 coverage & 92.9 & 94.5 & 88.3 & 91.8 & 98.3 & 95.4 & 96.8 & 100.2 \\
\hline PENTA 2 coverage & 88.5 & 92.5 & 86.7 & 84.3 & 84.7 & 90.2 & 90.9 & 101.5 \\
\hline PENTA 3 coverage & 106.9 & 96.2 & 89.9 & 92.1 & 88.8 & 85.7 & 93 & 106.5 \\
\hline MR 1 coverage & 86 & 91.5 & 82.5 & 97.3 & 93.2 & 91 & 88.8 & 108.4 \\
\hline PENTA 3 dropout rate & -15.1 & -1.8 & -1.8 & -0.28 & 9.7 & 10.2 & 3.9 & -6.3 \\
\hline MR dropout rate & 7.4 & 3.2 & 6.6 & -6.0 & -5.2 & -4.6 & 8.3 & -8.2 \\
\hline
\end{tabular}

Source: DHIS2 accessed on 16th March 2019

combination of approaches to reach everyone targeted for immunization" [33] in these communities to track newborns for immunization with birth doses (upto 2 weeks) as per the routine immunization schedule [34].

This study revealed wide variances (over 10\% difference between the two comparison months and the other months as per the county's overage coverage) in Pentavalent 3 coverage, Measles/Rubella 1 coverage and the fully immunized children in the two periods. This indicates that there is a large population unreached with the routine facility - based fixed immunization services in the settings. In the implementation of REC strategies, facilities and stakeholders must reconsider the sustainable measures that can complement the routine fixed immunization services in facilities to reach all eligible populations with immunizations. Inconvenient schedules, time constraints between daily socio - economic engagements against seeking immunization services in health facilities have been documented elsewhere as key to seeking immunization services [35]. More emphasis is required during the microplanning for immunization services to ensure that facilities identify their challenges and local solutions including planning for regular outreach programs to reach this needy population with immunization services $[28,36]$.

This study also showed large differences between the Pentavalent 3 and Measles/Rubella drop - outs between the two periods in the facilities at 13.8 and $24.3 \%$ respectively. This is an indication that in this population, there is more of a problem with children completing the vaccination series. This finding is similar to a study conducted in 12 high risk health facilities in Congo [8]. Innovative strategies need to be formulated to minimize missed opportunities for vaccination services. These can include verification of the $\mathrm{MCH}$ booklet/records at any opportunity under 5 children present at the facility and integration of immunization services in outpatient departments to minimize drop - outs [31, 37].

Communication and community engagement are key elements of successful vaccine delivery $[10,12,31,37-$ 39]. Community health volunteers are often relied upon by health facilities for communicating with the public regarding vaccination services. Evidence has shown that community - based service delivery through community health workers can increase maternal, newborn and child health service including immunization utilization in rural, hard-to-reach areas [32, 37, 40]. Advocacy with local traditional and religious leaders, information sharing with communities and building community mobilization networks with support from community "gatekeepers" may help shed light on the felt needs of the communities and build trust between the community and the immunization program.

These findings raise questions about the effectiveness of the Reaching Every Child (REC) strategy, the key vaccine program implementation strategy, in Migori. REC has been extensively evaluated in rural, urban and social economic hard - to - reach settings [7-9, 12, 13, 41, 42] and relies upon 5 components: planning and management of resources, reaching target populations, linking services with communities, supportive supervision and monitoring for action, for improved vaccination. [39]. Linking services to communities in the urban and social - economic hard - to - reach settings poses a challenge owing to the migratory nature of the population for survival. In addition, use of data to inform siting of mobile outreaches to reach target populations is a weakness identified in the facilities. The effectiveness of REC hinges on clear demarcation of the community to be served, its catchment population for mobilization, planning and monitoring. Use of facility immunization performance data to identify pockets in the community with unvaccinated/unreached children can inform where to invest the constrained resources to improve immunization coverage and maximize impact.

Our findings also reveal that multiple REC strategies and targeted support to facilities or wards with poor immunization coverages and high drop - outs can sustain the subcounties' performance above the WHO target $80 \%$ [17]. For measles immunization in particularbearing in mind that near $90 \%$ coverage is considered necessary for herd immunity, additional actions including Child Health Days/Weeks, integration of vaccination 
in other child health activities and supplemental immunization activities and campaigns need to be viable complementary options to improve immunization coverage in these special populations [43].

The authors acknowledge the limitations of this study. These include the small number of link facilities that provided door - to - door services and the short interval for comparing the findings. Use of DHIS2 data is likely to have quality issues (timeliness, accuracy and completeness). However, the project team supported the subcounty teams conduct verifications with individual health facilities before entering in the health information system. The facility EPI targets assigned by the $\mathrm{MOH}$ departments are mere estimates based on available demographic data that may not be very accurate hence performance as per the results may be over $100 \%$ for some of the antigens.

\section{Conclusions}

Complementing the fixed - point facility immunization with a mobile immunization strategy improved the immunization access and utilization in the health facilities for all antigens. This study stimulates the applicability of some components of the REC approach in the 64 health facilities in Migori particularly the need for novel approaches to planning, calculating coverage, defaulter tracking and social mobilization in rural, urban and economic hard - to - reach environments and monitoring and evaluation of immunization performance using the modern visual applications for decision - making. A mobile immunization strategy underscores the importance of community - driven approaches to improve the access and utilization of immunization services.

\section{Recommendations}

Our findings call for the following key recommendations to improve the immunization services in the county with significant multiple hard to - reach hotspots: 1) Health facilities should actively use routine immunization data to identify hard - to - reach areas to be targeted with outreaches to improve immunization coverage; 2) Outreach (mobile) immunization services should be more flexible to change locations and times of services provision in conformity with the 'socio - economic' and migratory patterns of the residents; 3) Counties should invest more resources in strengthening the community health systems so that CHVs are motivated and retained to carry out demand creation, deliver community services, and that communities continue to demand and utilize health services among them immunization; 4) An in - depth qualitative analysis to understand the best strategies and solutions to guarantee a sustained access and utilization of immunization services for the special hard - to - reach populations.

\section{Abbreviations}

CHA: Community Health Assistant; CHV: Community Health Volunteer; Cl: Confidence Interval; DHIS: District Health Information System; FIC: Fully Immunized Child; KEPI: Kenya Expanded Programme on Immunization; MCH: Mother and Child Health; $\mathrm{MOH}$ : Ministry of Health; QGIS: Quantum Geographic Information System; REC: Reaching Every Child/Community; RED: Reaching Every District; RRI: Rapid Results Initiative

\section{Acknowledgements}

The authors acknowledge Dr. Elizabeth Mgamb (County Director of Health, Migori County), Tom Odhong (Community Health Strategy Focal Person, Migori County), Hezron Ochieng' (Community Health Strengthening Service Delivery Officer, Save the Children), all the eight subcounty medical officers of health, subcounty nursing officers, subcounty EPI coordinators, subcounty HRIOs and subcounty community health strategy focal persons for their valuable input during the enhanced door - to - door immunization services. The authors also acknowledge Georgina Wanza, Norah Adhiambo, Julius Ominde and Salome Ndombi (Monitoring, Evaluation and Learning) and the project service delivery officers for their valuable support in supervision and data management. The authors specially acknowledge the expert review provided by Sarah Mukisa and Martin Owino for their oversight in the overall manuscript development.

\section{Authors' contributions}

DNS: conceived the idea, designed the proposal, supervised defaulter tracing and household immunization, participated in data collection, performed data analysis and drafted the manuscript. DNS, EOO, AM, TM and PK conceived the idea, participated in the design of the intervention, supervised the defaulter tracing and household immunization. MM, EOO and SOO mapped the facilities through the QGIS methodology, monitored and supervised the data collection. DNS, MM, TM and PK supervised the analysis plan, prepared the report and carefully reviewed the manuscript. All authors read and approved the final manuscript.

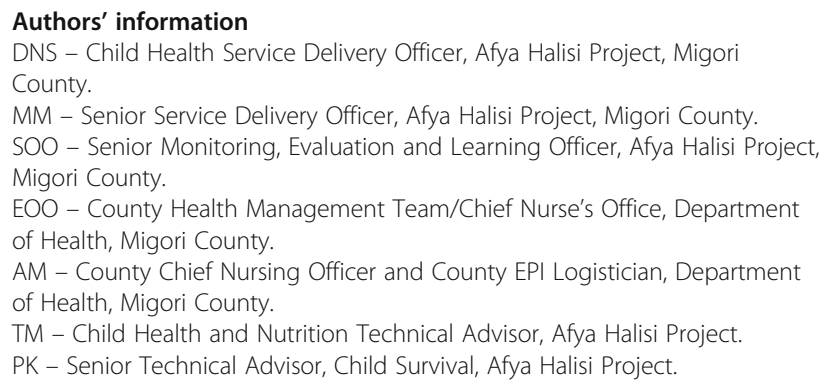

\section{Funding}

The United States Agency for International Development (USAID) funded the door - to - door immunization strategy through the Afya Halisi project. The design of the study and collection, analysis, and interpretation of data and in writing the manuscript has not been funded.

\section{Availability of data and materials}

The datasets used and/or analyzed during the current study are available from the corresponding author on reasonable request. The data was extracted from the Kenya Health Information System (KHIS), formerly the District Health Information System 2 (DHIS2), an open source public access system where all $\mathrm{MOH}$ reporting is done. The link to the databases used is https://hiskenya.org/dhis-web-pivot/.

\section{Ethics approval and consent to participate}

No institutional review board determination was sought for the study because the Kenya DHIS2 data are publically available [26], and the use of program reports in aggregate form was not human subjects' research [44, 45].

\section{Consent for publication}

Not applicable.

\section{Competing interests}

The authors declare that they have no competing interests. 


\section{Author details}

${ }^{1}$ Afya Halisi Project, Migori County, Kenya. ${ }^{2}$ Department of Health, Migori County, Kenya.

Received: 20 March 2019 Accepted: 31 July 2019

Published online: 07 August 2019

\section{References}

1. World Health Organization. Assessment Report of the Global Vaccine Action Plan: Strategic Advisory Group of Experts on Immunization, vol. 2018. Geneva: World Health Organization; 2018. Available from: https://apps.who. int/iris/bitstream/handle/10665/276967/WHO-IVB-18.11-ara.pdf

2. Bärnighausen T, Berkley S, Bhutta ZA, Bishai DM, Black MM, Bloom DE, et al. Reassessing the value of vaccines. Lancet Glob Health. 2014;2(5):e251-e2.

3. Control CD. Prevention. Vaccine preventable deaths and the global immunization vision and strategy, 2006-2015. MMWR Morb Mortal Wkly Rep. 2006;55(18):511.

4. UNICEF. Progress for children: a report card on immunization: UNICEF; 2005. Available from: https://scholar.google.com/scholar?hl=en\&as_sdt=0\%2C5 $\& q=U N I C E F .+$ Progress+for+children\%3A+A+report+card+on+ immunization\%3A+UNICEF\%3B+2005.\&btnG=

5. Wiysonge CS, Uthman OA, Ndumbe PM, Hussey GD. Individual and contextual factors associated with low childhood immunisation coverage in sub-Saharan Africa: a multilevel analysis. PLoS One. 2012;7(5):e37905.

6. UNICEF, World Health Organization. Progress and challenges with achieving universal immunization coverage: WHO/UNICEF estimates of national immunization coverage; 2017. (data as of July 2018) 2018. Available from: https://www.who.int/immunization/monitoring surveillance/who-immuniz.pdf

7. Ngomba AV, Kollo B, Bita AF, Djouma FN, Edengue JM, Elongue MJ, et al. Immunization programme in urban areas in Cameroon: a case study of the Djoungolo Health District. Pan Afr Med J. 2016;25:213.

8. Mwamba GN, Yoloyolo N, Masembe Y, Nsambu MN, Nzuzi C, Tshekoya P, et al. Vaccination coverage and factors influencing routine vaccination status in 12 high risk health zones in the province of Kinshasa City, Democratic Republic of Congo (DRC), 2015. Pan Afr Med J. 2017;27(Suppl 3):7.

9. Mutua MK, Kimani-Murage E, Ettarh RR. Childhood vaccination in informal urban settlements in Nairobi, Kenya: who gets vaccinated? BMC Public Health. 2011:11(1):6

10. Machingaidze S, Wiysonge CS, Hussey GD. Strengthening the expanded programme on immunization in Africa: looking beyond 2015. PLoS Med. 2013;10(3):e1001405.

11. Khan TM, Sahibzada MUK. Challenges to health workers and their opinions about parents' refusal of oral polio vaccination in the Khyber Pakhtoon Khawa (KPK) province, Pakistan. Vaccine. 2016;34(18):2074-81.

12. Fekadu L, Okeibunor J, Nsubuga P, Kipela JM, Mkanda P, Mihigo R. Reaching the unreached with polio vaccine and other child survival interventions through partnership with military in Angola. Vaccine. 2016;34(43):5155-8.

13. Babirye JN, Engebretsen IM, Rutebemberwa E, Kiguli J, Nuwaha F. Urban settings do not ensure access to services: findings from the immunisation programme in Kampala Uganda. BMC Health Serv Res. 2014;14(1):111.

14. World Health Organization. National immunization coverage scorecards estimates for 2017. Available from: https://apps.who.int/iris/bitstream/ handle/10665/276969/WHO-IVB-18.12-eng.pdf. Accessed 14 Nov 2018.

15. UNICEF. Humanitarian situation report: horn of Africa measles outbreak response. 2017Available from: https:/www.unicef.org/appeals/files/UNICEF_ Horn_of_Africa_Measles_Outbreak_Situation_Report_18_May_2017.pdf.

16. World Health Organization. Reaching every district (RED): a guide to increasing coverage and equity in all communities in the African region 2017. Available from: https://apps.who.int/iris/bitstream/handle/10665/26 0112/9789290233954-eng.pdf. Accessed 14 Nov 2018.

17. Global Vaccine Action Plan (GVAP) 2011-2020. Available from: https://www. who.int/immunization/global_vaccine_action_plan/GVAP_doc_2011_2020/ en/. Accessed 19 Nov 2018

18. World Health Organization. Regional strategic plan for immunization 2014-2020. Regional Office for Africa: World Health Organization; 2015. Available from: https://apps.who.int/iris/bitstream/handle/10665/204373/ 9789290232780.pdf

19. Kenya National Bureau of Statistics (KNBS) and ICF International. Kenya Demographic and Health Survey (KDHS) 2014. Available from: https:/ dhsprogram.com/pubs/pdf/fr308/fr308.pdf.
20. WHO Vaccine Preventable Diseases Monitoring System: 2018 global summary (data as of 2018). Available from: http://apps.who.int/ immunization_monitoring/globalsummary/countries?countrycriteria\%5 Bcountry\%5D\%5B\%5D=KEN.

21. Williams PC. The reality of the mortality statistics of the nurses' strike in Kenya. Lancet. 2017:390(10094):551.

22. Lancet T. Kenya's nurses strike takes its toll on health-care system. Lancet (London, England). 2017;389(10087):2350.

23. Ministry of Health (Kenya). Immunization manual for health workers. In: Division of vaccines and immunization; 2012.

24. Kenya Demographic and Health Survey 2014 County Level Fact Sheets. Available from: https://www.knbs.or.ke/download/2014-kdhs-county-levelfact-sheets/. Accessed 19 Nov 2018.

25. Ministry of Health (Kenya). The RRI Roadmap: National Accelerated Immunization Outreach Services. 2018.

26. Kenya Health Information System. Available from: https://hiskenya.org/dhisweb-pivot/. Accessed 29 May 2019.

27. Kenya National Bureau of Statistics. The 2009 Kenya population and housing census. Kenya National Bureau of Statistics Kenya; 2010.

28. World Health Organization. Microplanning for immunization service delivery using the reaching every district (RED) strategy. Geneva: WHO; 2009. Available from: https://apps.who.int/iris/bitstream/handle/10665/70450/ WHO_IVB_09.11_eng.pdf

29. Campbell MJ, Shantikumar S. Public health textbook: research methods. UK: University of Sheffield; 2016. Available from: https://www.healthknowledge. org.uk/public-health-textbook/research-methods/1b-statistical-methods/ parametric-nonparametric-tests

30. Haydarov R, Anand S, Frouws B, Toure B, Okiror S, Bhui BR. Evidence-based engagement of the Somali pastoralists of the horn of Africa in polio immunization: overview of tracking, cross-border, operations, and communication strategies. Glob Health Communication. 2016;2(1):11-8.

31. Nnadi C, Etsano A, Uba B, Ohuabunwo C, Melton M, wa Nganda G, et al. Approaches to vaccination among populations in areas of conflict. J Infect Dis. 2017;216(suppl_1):S368-S72.

32. McArthur-Lloyd A, MCKenzie A, Findley SE, Green C, Adamu F. Community engagement, routine immunization, and the polio legacy in northern Nigeria. Glob Health Communication. 2016;2(1):1-10.

33. World Health Organization. Periodic intensification of routine immunization lessons learned and implications for action. 2009. Available from: http:// www.immunizationbasics.jsi.com/Docs/PIRImonograph_Feb09.pdf.

34. Rainey J, Bhatnagar P, Estivariz C, Durrani S, Galway M, Sandhu H, et al. Providing monovalent oral polio vaccine type 1 to newborns: findings from a pilot birth-dose project in Moradabad district, India. Bull World Health Organ. 2009;87:955-9.

35. Babirye JN, Rutebemberwa E, Kiguli J, Wamani H, Nuwaha F, Engebretsen IM. More support for mothers: a qualitative study on factors affecting immunisation behaviour in Kampala, Uganda. BMC Public Health. 2011;11(1):723.

36. Alfred K, Tabu S, Paul KM, Irene M, Robert T, Peter KK, et al. Utilization of essential immunization services among children under five years old in Kacheliba division, Pokot County. Kenya: DSpace Repository for Moi University School of Public Health; 2014. http://ir.mu.ac.ke:8080/xmlui/ handle/123456789/939.

37. Hussain SF, Boyle P, Patel P, Sullivan R. Eradicating polio in Pakistan: an analysis of the challenges and solutions to this security and health issue. Glob Health. 2016;12(1):63.

38. WHO. Microplanning for immunization service delivery using the reaching every district (RED) strategy. Geneva: World Health Organization; 2009.

39. WHO. Reaching every district (RED): a guide to increasing coverage and equity in all communities in the African region. 2017.

40. Uzondu CA, Doctor HV, Findley SE, Afenyadu GY, Ager A. Female health workers at the doorstep: a pilot of community-based maternal, newborn, and child health service delivery in northern Nigeria. Glob Health Sci Pract. 2015:3(1):97-108.

41. Ryman TK, Trakroo A, Wallace A, Gupta SK, Wilkins K, Mehta P, et al. Implementation and evaluation of the reaching every district (RED) strategy in Assam, India, 2005-2008. Vaccine. 2011;29(14):2555-60.

42. Ryman T, Macauley R, Nshimirimana D, Taylor P, Shimp L, Wilkins K. Reaching every district (RED) approach to strengthen routine immunization services: evaluation in the African region, 2005. J Public Health. 2009;32(1):18-25. 
43. Oliphant NP, Mason JB, Doherty T, Chopra M, Mann P, Tomlinson M, et al. The contribution of child health days to improving coverage of periodic interventions in six African countries. Food Nutr Bull. 2010;31(3_suppl3): S248-S63.

44. Kanyuuru L, Kabue M, Ashengo TA, Ruparelia C, Mokaya E, Malonza I. RED for PMTCT: an adaptation of immunization's reaching every district approach increases coverage, access, and utilization of PMTCT care in Bondo District, Kenya. Int J Gynecol Obstet. 2015;130:S2.

45. Association WM. World Medical Association Declaration of Helsinki. Ethical principles for medical research involving human subjects. Bull World Health Organ. 2001;79(4):373.

\section{Publisher's Note}

Springer Nature remains neutral with regard to jurisdictional claims in published maps and institutional affiliations.

Ready to submit your research? Choose BMC and benefit from:

- fast, convenient online submission

- thorough peer review by experienced researchers in your field

- rapid publication on acceptance

- support for research data, including large and complex data types

- gold Open Access which fosters wider collaboration and increased citations

- maximum visibility for your research: over $100 \mathrm{M}$ website views per year

At $\mathrm{BMC}$, research is always in progress.

Learn more biomedcentral.com/submissions 